\title{
Practice Recommendations for Handling of Expressed Human Milk in Healthcare Facilities
}

\author{
This position statement was developed by the \\ IPAC Canada Paediatric and Neonatal Interest Group: \\ Chair/Contact: Madeleine Ashcroft/Anne Augustin \\ Principal Authors: Anne Augustin, Yameen AlMatawah, \\ Clare Barry, Melanee Eng-Chong, Connie Gittens, Eva Hatzis, \\ Crystelle Ong, Laurie Streitenberger, and Cara Sudoma
}

\section{Publication Date}

Original: October 2006

Revised: 2013, 2015, 2020 in collaboration with Standards and Guidelines Committee

Disclaimer: This document was developed by IPAC Canada based on best available evidence at the time of publication to provide advice to Infection Prevention and Control Professionals. The application and use of this document are the responsibility of the user. IPAC Canada assumes no liability resulting from any such application or use.

\section{BACKGROUND}

Human milk is an important source of nutrition and immunological protection for an infant. It can also be a source of infection [1-5]. Since human milk is a body fluid, many aspects of handling human milk in healthcare facilities are guided by practices used for other body fluids, e.g., blood, blood transfusions $[3,4,6]$.

\section{INFECTION PREVENTION AND CONTROL} RECOMMENDATIONS FOR HANDLING OF EXPRESSED HUMAN MILK IN HEALTHCARE FACILITIES To minimize the risk of spreading infection in healthcare facilities, the principles listed below should be followed. Each facility should take these principles into consideration when making policy decisions regarding the safe handling of expressed human milk.

\section{Collection}

- Mothers should be taught the basic principles of asepsis (hand hygiene and "no-touch technique") as it applies to collection, storage and handling of human milk [1-3,6].

- Expressed human milk should be collected and stored in sterile glass or plastic containers for consumption by infants in NICU or other critical care settings [6, 7]. For other settings, clean containers are acceptable [6].
- All containers used for expressed human milk collection and storage should be free of bisphenol A (BPA) $[1,3,6,8]$ and made specifically for human milk storage leaving approximately $3 \mathrm{~cm}$ of space from the top, or as per the manufacturers' directions for use [6].

- To determine if plastic container contains BPA, consider reviewing information at: http://healthycanadians. gc.ca/environment-environnement/home-maison/ bisphenol_a-eng.php

- The container should be labelled to include contents, baby's name, mother's name, healthcare facility identifier, date/time of pumping, date/time of freezing, date/time of thawing, and medications or supplements being taken by the mother $[1-3,6]$.

\section{Storage}

- Freshly expressed human milk should be used within 48 hours and stored in a dedicated commercial refrigerator between $2^{\circ} \mathrm{C}$ and $4^{\circ} \mathrm{C}$, otherwise frozen in a dedicated commercial freezer between $-17^{\circ} \mathrm{C}$ and $-20^{\circ} \mathrm{C}$ [6]. It can be kept for up six to 12 months in a deep freezer. The temperature of the refrigerator and freezer is to be monitored according to facility policy and daily as a minimum [6].

- It is essential that the human milk remain chilled or frozen during transport. Freezer gel packs are preferable 
to ice as freezer gel packs have a lower freezing temperature; ice is warmer than frozen milk and may thaw the frozen milk $[6,9]$.

- Frozen human milk should be thawed in the refrigerator or a waterless, temperature-controlled human milk warmer following the manufacturer's guidelines. Thawed human milk, maintained in the refrigerator, is to be used within 24 hours of thawing in the refrigerator (i.e., from the time it is completely thawed, not from the time when it comes out of the freezer) [6,9]. Frozen human milk should not be thawed in a microwave oven, or in boiling water [6].

- If unexpected thawing occurs, fully thawed milk that has maintained a temperature of $4^{\circ} \mathrm{C}$ or below may be used within 24 hours of thawing, otherwise it must be discarded [6].

- Unrefrigerated fresh human milk should be used within four hours or discarded [6].

- Previously thawed human milk should not be left at room temperature for more than four hours because of the reduced ability to inhibit bacterial growth [6].

- Expressed human milk that has been fortified should be refrigerated and used within 24 hours of preparation or thawing, whichever is sooner $[6,9]$.

- Each mother should be assigned a dedicated, labelled freezer container for her baby's milk. The dedicated container should be cleaned, at minimum, when visibly dirty and between mothers.

\section{Preparation}

- Handle all additives used for fortifying human milk using aseptic technique [9-11].

- Dedicated centralized space for human milk and formula preparation is required. This ensures safe, accurate, and consistent preparation technique. The space is to be within the unit or other location physically separate from direct patient care and used only for the purpose of preparing human milk and formula by aseptic technique [6]. Design is to follow the CSA Z8000 - 18.

- The preparation area should consist of stainless steel or other non-porous work surfaces. All equipment for mixing and measuring should be made of stainless steel or BPA-free plastic to allow for proper cleaning and sanitizing.

- If human breast milk and formula preparation room exclusively uses single-use devices or disposable bottles and supplies, a commercial dishwasher is not mandatory [6].

- If using reusable utensils and supplies, a commercial-grade dishwasher capable of reaching a temperature of $82^{\circ} \mathrm{C}$ is preferred [6].

- Use of a facility's food service dishwasher is not recommended. If it is necessary to use the food service dishwasher, practices are required to prevent crosscontamination and ensure sanitization o Equipment may be hand-washed and autoclaved or sanitized using a three-compartment sink (wash, rinse, chemically sanitize) process as an alternative to a commercial dishwasher [6].

\section{Providing Feed}

- Warming of human milk and formula feeds promotes accelerated bacterial growth. If feedings are warmed, the process should take less than 15 minutes and the feedings should not be warmed to greater than $40^{\circ} \mathrm{C}$ [6].

o Multi-bottle water baths are discouraged, however, if they are used, care should be taken to protect the bottles from direct contact with the water to avoid contamination [6].

o Never warm in a microwave oven [6].

o Do not warm in the infant's bed (e.g., isolette, over-bed warmer)

- The maximum hang time for continuous feedings is four hours. The administration set should be changed every four hours $[6,9]$.

- When administering expressed human milk, principles of Routine Practices should be followed [12,13].

- At a minimum, a double check mechanism should be used at the time of administration to avoid errors in administration. In facilities with large numbers of mothers who express milk, consideration should be given to automated systems such as bar coding to avoid errors in administration [6].

- A comprehensive written policy, including disclosure and course of action should be available in the event of errors involving human milk (e.g., an infant consumes expressed human milk that is not from their mother). Viral testing of "donor" and "recipient" mothers should occur as well as administration of post-exposure prophylaxis, if indicated $[1,3,9]$.

\section{Environmental Cleaning}

\section{Feed Preparation Area}

- Milk preparation areas may become contaminated and must be cleaned daily and between the preparations of milk from different mothers [12].

- Refrigerators and freezers used for breast milk should have a regular cleaning schedule and must not be used for storing other items such as food, specimens or medications [12].

- Hospital cleaning and disinfecting products used in the healthcare setting must be approved by IPAC and Occupational Health and Safety [12]. The hospital disinfectants must have a Drug Identification Number (DIN) from Health Canada [14].

- Phenolics should not be used in nurseries or the NICU because absorption through the skin can cause hyperbilirubinemia [12].

- Cleaning and disinfecting agents may be combined into a single product, thus saving a step in the process. Cleaning and disinfecting protocols should allow for the full contact time specified for the product used [12].

- Products that leave no toxic residues should be selected for cleaning and disinfecting newborn areas and equipment [12]. 


\section{Breast Kits}

- Breast pump kits are considered single-patient use (i.e., used by one mother for her specific infant[s]. Each healthcare facility must provide education and training on how to clean, sanitize/disinfect, dry (air dry away from a water source) and store the kits safely between each use of the breast pump kit by the same mother. Alternatively, disposable/single-use breast pump kits are acceptable $[6,15]$.

- Breast pump tubing and membrane filters can be difficult to clean adequately, depending on the make of pump and facility reprocessing expertise. They should be discarded if they come into contact with human milk, or if there are issues related to their physical integrity.

- The breast pump should be cleaned with a low-level disinfectant after each use [12].

- Breast pump kits cannot be used by multiple mothers unless reprocessing (cleaning, disinfection/sterilization) can be validated according to the manufacturer's instructions $[13,15,16]$.

\section{Donor Milk}

Donor human milk from Canadian milk banks is only available by prescription and according to a specified need. These milk banks abide by strict operating procedures (i.e., Human Milk Banking Association of North America Guidelines), which include donor screening, medical supervision, bacteriological testing, pasteurization, storage, and distribution. Before their infant receives donor human milk, parents are to be informed of the benefits and the potential risks. A written informed consent from parents/ guardians must always be obtained before the administration of human donor milk $[9,12]$.

Health Canada strongly recommends against the sharing and consumption of unprocessed donor human $[17,18]$.

\section{Auditing}

Feed collection, storage, preparation, and provision processes are to be routinely audited; the audit results evaluated, and required corrective actions taken to improve practice [6].

Frequent audits of cleaning practice should be included as part of the organization's responsibility for maintaining a clean feed preparation environment [14].

\section{GLOSSARY}

Single-Patient Use: A term given to medical equipment/devices that may be used on a single client/patient and may be reused on the same client/patient, but may not be used on other clients/patients.

Single use/Disposable: A term given to medical equipment/devices designated by the manufacturer for single use only.

Single-use equipment/devices must not be reprocessed.

\section{As per the Canadian Standard Association (CSA):}

"SHALL" is used to express a requirement, i.e., a provision that the user is obliged to satisfy in order to comply with the standard;
"SHOULD" is used to express a recommendation or that which is advised but not required; and "MAY" is used to express an option or that which is permissible within the limits of the standard, an advisory or optional statement.

\section{REFERENCES}

1. Kimberlin DW, Brady MT, Jackson MA, Long SS, editors. Red Book: 2018 report of the committee on infectious diseases. 31st ed. Elk Grove Village, IL: American Academy of Pediatrics; 2018.

2. American Academy of Pediatrics, American College of Obstetricians and Gynecologists. Guidelines for perinatal care. 8th ed. Elk Grove Village, IL: American Academy of Pediatrics; 2017.

3. Canadian Pediatric Society. Position Statement: Human milk banking [Internet]. 2010 Nov 12010 [Reaffirmed 2018 Feb; cited 2020 Aug 28]. Retrieved from: https://www.cps.ca/ en/documents/position/human-milk-banking

4. Barry C. et al. Management of EBM: Is the right breast milk being fed to infants? (1998). Canadian Journal of Infection Control, 13(1), 16-19.

5. Ogundele M. (2000). Techniques for the storage of human breast milk: Implications for anti-microbial functions and safety of stored milk. European Journal of Pediatrics, 159(11),793-797.

6. Steele C, Collins E, editors. Pediatric Nutrition Dietetic Practice Group of the American Dietetic Association. 3rd ed. Infant and Pediatric Feedings: Guidelines for preparation of human milk and formula in health care facilities. 2019.

7. Cossey V, Jeurissen A, Thelissen MJ, Vanhole C, Schuermans A. (2011). Expressed breast milk on a neonatal unit: A hazard analysis and critical control points approach. American Journal of Infection Control, 39,832-838.

8. Government of Canada. Bisphenol A (BPA) [Internet]. 2018 Dec 31 [cited 2020 Aug 28]. Retrieved from: http://healthycanadians.gc.ca/environment-environnement/ home-maison/bisphenol_a-eng.php

9. Human Milk Banking Association of North America. Best practice for expressing, storing and handling of human milk in hospitals, homes, and child care settings. 4th ed. HMBANA. Fort Worth: 2019. Retrieved from: https://www.hmbana.org/ our-work/publications.html

10. Government of Canada [Internet]. Recommendations for the preparation and handling of powdered infant formula (PIF). 2010 Feb 15 [cited 2020 Aug 28]. Retrieved from: http:// www.hc-sc.gc.ca/fn-an/nutrition/infant-nourisson/pif-ppnrecommandations-eng.php

11. Centers for Disease Control and Prevention. (2002). Enterobacter sakazakii Infections associated with the use of powdered infant formula - Tennessee, 2001. MMWR, 51(14),298-300.

12. Ontario Agency for Health Protection and Promotion (Public Health Ontario), Provincial Infectious Diseases Advisory Committee. Best practices for infection prevention and control 
in perinatology in all health care settings that provide obstetrical and newborn care. Toronto, ON: Queen's Printer for Ontario; 2015 [cited 2020 Aug 28]. Retrieved from: https://www.publichealthontario.ca/-/media/ documents/bp-ipac-perinatology.pdf?la =en

13. Ontario Agency for Health Protection and Promotion (Public Health Ontario), Provincial Infectious Diseases Advisory Committee. Routine practices and additional precautions in all health care settings. 3rd ed. Toronto, ON: Queen's Printer for Ontario; 2012 [cited 2020 Aug 28]. Retrieved from: https://www.publichealthontario. $\mathrm{ca} /$-/media/documents/bp-rpap-healthcare-settings. pdf?la $=$ en

14. Ontario Agency for Health Protection and Promotion (Public Health Ontario), Provincial Infectious Diseases Advisory Committee. Best practices for environmental cleaning for prevention and control of infections in all health care settings. 3rd ed. Toronto, ON: Queen's Printer for Ontario; 2018 [cited March 13, 2020]. Retrieved from: https://www.publichealthontario.ca/-/ media/documents/bp-environmental-cleaning.pdf?la $=$ en
15. Doxtator L, Zoutman D. (2006). Management of breast pump kits: a review. Canadian Journal of Infection Control, 21(2), 92-95.

16. Ontario Agency for Health Protection and Promotion (Public Health Ontario), Provincial Infectious Diseases Advisory Committee. Best practices for cleaning, disinfection and sterilization of medical equipment/devices. 3rd ed. Toronto, ON: Queen's Printer for Ontario; 2013 [cited 2020 Aug 28]. Retrieved from: www.publichealthontario.ca/en/eRepository/ PIDAC_Cleaning_Disinfection_and_Sterilization_2013.pdf

17. Keim SA, Hogan JS, McNamara KA, Gudimetla V, Dillon CE, Kwiek JJ, et al. (2013). Microbial contamination of human milk purchased via the internet. Pediatrics, 132(5),1227-1235.

18. Health Canada. Laboratory Centre for Disease Control, Division of Nosocomial and Occupational Infections. Infection control guidelines. Hand washing, cleaning, disinfection and sterilization in health care. Can Commun Dis Rep. 1998 [cited 2020 Aug 28];24 Suppl 8:1-54. Retrieved from: http://publications. gc.ca/collections/collection_2016/aspc-phac/HP3-1-24-S8eng.pdf 